3. Karande V., Nikumbha V.P., Desai A. el all. (2017), "Study of surgical management of malleolar fractures of ankle in adults", Int J Orthop Sci, 3(3), 783-787.

4. Bartoniček J., Rammelt S., Tuček M. el all. (2015), "Posterior malleolar fractures of the ankle", Eur J Trauma Emerg Surg, 41(6), 587-600.

5. Ma Ngọc Thành (2010), Đánh giá kết quả phẫu thuật gãy kín mắt cá chân tại bệnh viện hữu nghi Việt Đức, Luân văn thạc sĩ y hooc đaji học y Hà Nội.

6. Đố Tuấn Anh (2016). Kết quả phẩu thuật gãy kín xương mắt cá chân ở người trưởng thành tại bệnh viện Hữu nghị Việt Đức. Luận văn thạc sĩ y học đại học y Hà Nối.

7. SooHoo N.F., Krenek L., Eagan M.J. et all (2009). "Complication Rates Following Open Reduction and Internal Fixation of Ankle Fractures". JBJS, 91(5), 1042-1049.

8. Samuel B. Adams., David. M. Tainter, Michel A. Taylor (2020) "'Malleolar Fractures and Soft Tissue Injuries of the Ankle'"', Skeletal Trauma, 6 Edition; Chapter 66: 2446- 2484.

\title{
PHẪU THUÂT THU GỌN VÚ SỬ DỤNG VẠT MANG PHỨC HỢP QUÂNG NÚM VÚ TRỤC MẠCH NGỰC TRONG
}

\section{Trần Thiết Sơn*, Trương Thế Duy*, Phạm Thị Việt Dung*, Tạ Thị Hồng Thúy*, Vũ Hồng Chiến** \\ INTERNAL THORACIC ARTERY AXIAL PATTERN FLAP CARRYING NIPPLE AREOLA COMPLEX}

\section{TÓM TẮT}

Bài báo nhằm đánh giá đặc điểm vạt mang phức hợp quầng núm vú của động mạch ngực trong và kết quả sử dụng vạt mang phưưc hợp quầng núm vú trục mach ngức trong trong phâuu thuât thu gon vú phì đai. Tiển hành trên 30 bệnh nhân với 60 vú phì đại được thu gọn bằng vat phức hợp quầng núm vú trục mạch ngực trong tại bệnh viện Xanh Pôn và bệnh viện Bạch Mai từ 01/2017 đến 06/2021. Mức đô phì đai nhiều, rất nhiều chiếm 45 vú $(70 \%)$ và khổng lồ 14 vú $(23,3 \%)$. Trên siêu âm doppler cầm tay: $100 \%$ động mạch ngực trong cho nhánh nuôi vào quâng núm vú từ các phía: trên $(11,67 \%)$, trên trong $(75 \%)$ và trong (13,33\%). 20 động mạch vú trong của 10 bệnh nhân được khảo sát trên phim MSCT, nhánh vào quầng núm vú chủ yếu thuộc KLS II, III, 95\% có đường kính mach trên $1,5 \mathrm{~mm}$. Vat phức hợp quầng núm vú truc mach ngực trong thiết kế dưới 3 dạng theo hướng vào quầng núm vú của trục mạch: $45 / 60$ (75\%) cuống trên trong, 7/60 (11,67\%) cuống trên, 8/60 (13,33\%) cuống trong. 45/60 (75\%) Vạt có tỷ lệ dài/rông > 2/1, lớn nhất tới 4,43/1. 100\% Quầng núm vú sống. 14/60 quầng núm vú $(23,3 \%)$ bị rối loạn cảm giác. Sau 3 tháng, 8/14 quầng núm vú rối loạn cảm giác được phục hồi. Tóm lại, động mạch ngực trong rât đáng tin cậy trong cấp máu quâng núm vú. Thu gọn vú sử dụng vạt mang phức hợp quâng núm vứ trục mạch ngực trong đảm bảo sức sống và di chuyển linh động quầng núm vú, có thể áp dụng cho mọi mức độ vú phì đại.

Tư' khóa: Phì đại tuyến vú, phức hợp quầng núm vú, vạt trục mạch ngực trong.

\section{SUMMARY \\ BREAST REDUCTION SURGERY USING THE}

*Trường Đại học Y Hà Nội

**Bênh viện Bach Mai

Chịu trách nhiệm chính: Trương Thế Duy,

Email: theduytruonghmu@gmail.com

Ngày nhan bài: 9/8/2021

Ngày phản biên khoa hoc: 30/8/2021

Ngày duyệt bài: 28/9/2021
This article aims to evaluate the characteristics of blood supply to the nipple areola complex of the internal thoracic artery and the effectiveness of using internal thoracic artery axial pattern flap carrying the nipple areola complex in hypertrophy breast reduction performed in 30 patients with 60 hypertrophic breasts at Saint Paul hospital and Bach Mai hospital from January 2017 to June 2021 . Hypertrophic breasts were operated on including 45 high/very high breasts $(70 \%)$ and 14 giant breasts $(23.3 \%)$. The vascular axis was determined by hand-held doppler ultrasound: $100 \%$ of the nipple areola complex was supplied by anterior intercostal branches of the internal thoracic artery from the sides: superior (11.67\%), superomedial (75\%) and medial (13.33\%). 20 internal thoracic arteries of 10 patients were analyzed on MSCT, the branches entering the nipple areola complex mainly passed through the second and third intercostal spaces. $95 \%$ of them had vessel diameters greater than $1.5 \mathrm{~mm} .45$ flaps (75\%) had length/width ratio $>2 / 1$, the largest up to $4.43 / 1$. $100 \%$ of the nipple areola complex are survival. Sensory disturbances occurred in 14/60 nipple areola complex $(23.3 \%)$. After 3 months, $8 / 14$ of these nipples were restored to normal sensation. In summary, the internal thoracic artery is reliable in the nipple areola complex blood supply. Hypertrophy breast reduction using the internal thoracic artery axial pattern flap carrying the nipple areola complex ensures vitality and mobility of the nipple areola complex and can be applied to all degrees of breast hypertrophy.

Keywords: Hypertrophy breast, nipple areola complex, internal thoracic artery axial flap

\section{I. ĐĂT VẤN ĐỀ}

Phì đại vú là tình trạng tăng thể tích bất thường do quá phát mô tuyến cùng thâm nhiễm tổ chức mõ̃, gây hậu quả biến dạng và sa trễ bầu vú, thay đổi vị trí của phức hợp quầng núm vú (QNV). Vú phì đại gây rối loạn về chức năng 
và thẩm mỹ, ảnh hưởng đến các hoạt động thể chất, sinh lý. Phẫu thuật là biện pháp điều trị hiệu quả duy nhất [1]. Phẫu thuật thu gọn vú lần đầu được thực hiên vào thế kỷ XVII chỉ đơn thuần là cắt một phần tuyến vú mà không can thiệp gì vào da hay QNV. Đến thế kỷ XX thu gọn vú mới thực sự phát triển mạnh. Năm 1922, Thorek lần đầu thực hiên thu gọn vú và chuyển QNV đến vị trí mới như một mảnh ghép da rời, tuy nhiên, có nhược điểm làm mất cảm giác QNV, mất khả năng tiết sữa, giảm độ nhô và mất sắc tố QNV [2]. Năm 1930, Schwartz-mann thu gọn vú bằng sử dụng vạt mang phức hợp QNV để tái tạo lại hình thể vú và dịch chuyển QNV lên vị trí mới [3]. Từ đó, rất nhiều loại cuống vạt ra đời dưới dạng ngẫu nhiên. Với vú phì đại mức độ vừa đến nhiều có thể thực hiện thu gọn vú bằng tạo vat cuống ngẫu nhiên [4]. Tuy nhiên, với vú phì đại rất nhiều và khổng lî̀, sa trễ nặng, sử dụng vạt cuống ngẫu nhiên có nguy cơ cao hoại tử QNV do tỷ lệ dài/rộng vạt > 2/1 không đảm bảo cấp máu QNV, vì vậy, các tác giả trên thế giới vẫn dùng kỹ thuât Thorek. Dựa trên nghiên cứu giải phẫu cấp máu QNV, chúng tôi đã thành công trong sử dụng kỹ thuật tạo vạt trục mạch mang phức hợp QNV. Cho đến hiện nay, chưa có công bố trên thế giới về sử dụng vạt mang phức hợp QNV dưới dạng có trục mạch nói chung và vạt mang phức hợp QNV trục mạch ngực trong nói riêng. Vì vậy, bài báo này ra đời nhằm báo cáo hiệu quả sử dụng kỹ thuật tạo vạt phức hợp QNV trục mạch ngực trong dựa trên đặc điểm ưu thế cấp máu cho QNV của động mạch (ĐM) ngực trong.

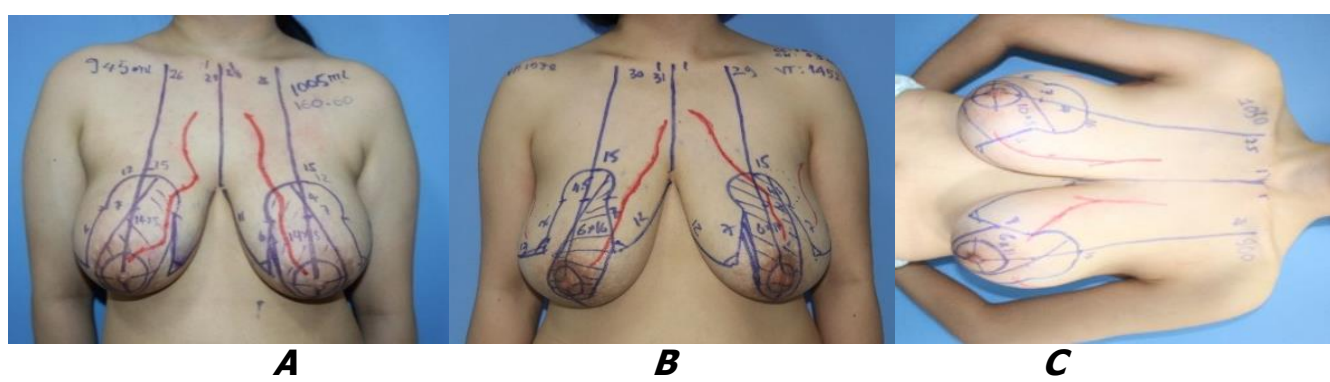

Hình 1. Các dạng thiết kế cuống linh động của vạt QNV trục mạch ngực trong

A. Cuống trên trong (2 bên) B. Cuống trên $(T)$, cuống trên trong $(P)$

C. Cuống trong $(\mathrm{P})$, cuống trên trong $(\mathrm{T})$

- Phẫu thuật: Dưới mê nội khí quản, bệnh nhân nằm ngửa dang tay. Rạch da theo đường thiết kế, lạng bỏ thượng bì ở vùng thân vạt và để lại da vùng phức hợp QNV. Cắt bỏ mô thừa xung quanh vạt, gồm: da, mõ và tuyến ở cực dưới, cực trên-ngoài. Bóc tách vạt khỏi mạc ngực vừa đủ đạt di dộng vạt. Cầm máu vết mổ. Xoay cuộn
II. ĐỐI TƯỢNG VÀ PHƯƠNG PHÁP NGHIÊN CỨU

2.1 Đối tượng nghiên cứu: 30 bênh nhân với 60 vú phì đại được thu gọn sử dụng vạt phức hợp QNV trục mạch ngực trong, tại bệnh viện Xanh Pôn và bệnh viện Bạch Mai từ tháng 01/2017 đến tháng 08/2021. Chụp MSCT khảo sát ĐM ngực trong được thực hiện trên 10 bệnh nhân tại bệnh viện Bạch Mai.

2.2 Phương pháp nghiên cứu: Nghiên cứu can thiệp lâm sàng không đối chứng kết hợp hồi cứu và tiến cứu

- Chuẩn bị trước mổ: Đo thể tích vú, phân độ phì đai và sa trễ. Đo các chỉ số: Khoảng cách từ bờ dưới xương đòn cách đầu trong $5 \mathrm{~cm}$-núm vú (trục núm vú), đâuu trong xương đòn-núm vú, QNV-Nếp lằn vú, khoảng cách 2 núm vú...

Xác định trục mạch: là nhánh xuyên khoang liên sườn (KLS) vào QNV của ĐM ngực trong được xác định bằng siêu âm doppler cầm tay và chụp MSCT động mạch cấp máu QNV.

Thiết kế vạt mang phức hợp QNV trục mạch ngực trong: Đường rạch $T$ ngược: vị trí cực trên QNV mới nằm trên trục núm vú từ $15-16 \mathrm{~cm}$ đến xương đòn, đường kính QNV mới 4,5-5cm và chu vi ổ khóa tương ứng. 2 ngành bên với chiều cao từ $6-7 \mathrm{~cm}$ (đường sẹo dọc), chiều dài tương ứng nửa trong và ngoài đường sẹo ngang. Thiết kế vạt phức hợp QNV dưới dạng da-tổ chức dưới da và một phẩn tuyến với trục mạch đã được xác định. Một trong 3 dạng vạt mang phức hợp QNV được sử dụng dựa theo hướng đi vào QNV của mạch trục là: cuống trên, cuống trên trong, cuống trong. vạt ra ngoài, lên trên để đạt 2 mục đính: chuyển vị QNV lên trên vào vị trí mới và tái tạo hình thể bầu vú mới. Khâu đính 2 ngành bên tại các giao điểm sẹo dọc - QNV và sẹo dọc-sẹo ngang. Khâu QNV vào vị trí QNV mới. Đặt dẫn lưu áp lực âm. Khâu đóng vết mổ theo lớp giải phẫu. 

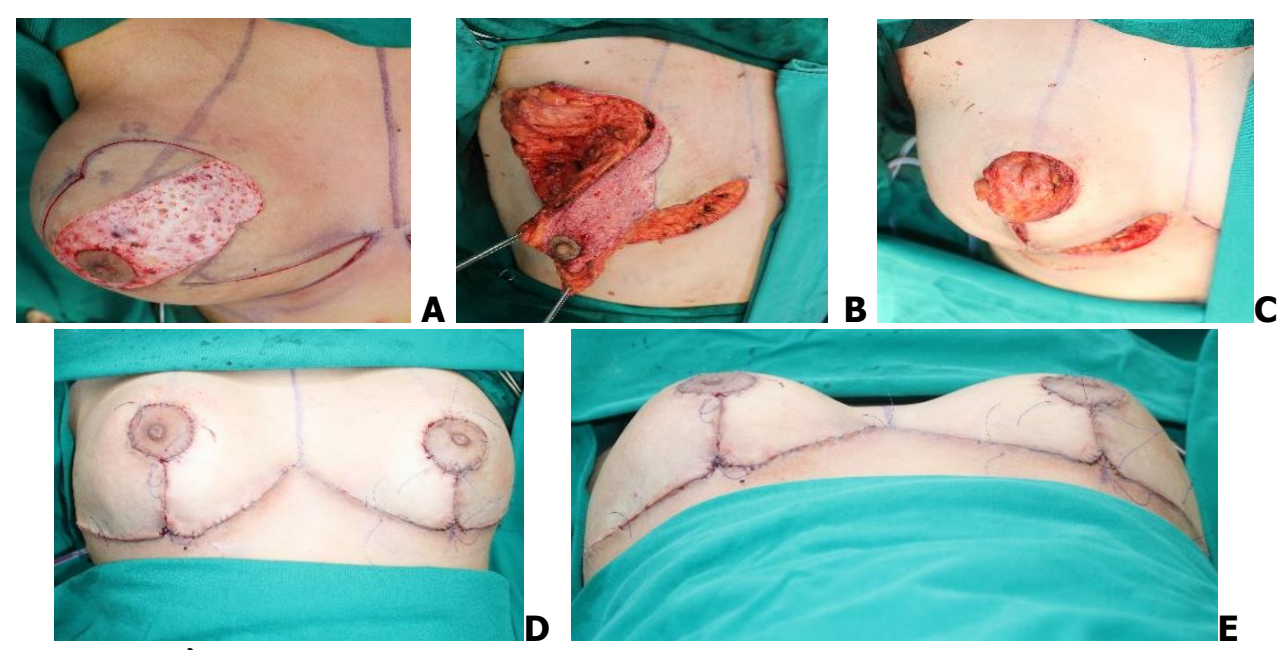

Hình 2. Trong mổ thu gọn vú bằng vạt QNV trục mạch ngực trong với sẹo T ngược; $\mathbf{A}$. Lạng bỏ thượng bì vat $\mathbf{B}$. Bộc lộ vạt, cắt bỏ tuyến da thừa; $\mathbf{C}$. Tạo hình thể bầu vú mới bằng cuộn vạt D. Hình thể sau mổ tư thể nằm (nhìn từ trên); $\mathbf{E}$. Hình thể sau mổ tư thế nằm (nhìn từ dưới)

\section{- Đánh giá kết quả:}

Ngay sau mổ: sức sống QNV, tình trạng vết mổ, cảm giác QNV.

Sau 3 tháng: phục hồi cảm giác, hình thể vú, sẹo, sự hài lòng của bệnh nhân.

\section{KẾT QUẢ NGHIÊN CỨU}

Trên tổng số 30 bệnh nhân nghiên cứu $(60$ vú): $20 / 60(33,3 \%)$ vú phì đại nhiều, $25 / 60$ $(41,7 \%)$ vú phì đại rất nhiều, $14 / 60(23,3 \%)$ vú phì đại khổng lồ.

Trên 10 phim chụp MSCT khảo sát 20 ĐM ngực trong của 20 vú: $100 \%$ ĐM ngực trong đều cho nhánh nuôi vào QNV với tổng 27 nhánh xuyên KLS vào QNV. Trong đó, qua KLS III chiếm 12/27 (44,44\%), qua KLS II 9/27 $(33,33 \%)$ và qua KLS I 6/27 (22,22\%). Các nhánh xuyên vào QNV đi rất nông dưới da trong khoảng 1 đến $26 \mathrm{~mm}$, đường kính mạch trung bình: $1.76 \mathrm{~mm} \pm 0,24 \mathrm{~mm}$ với tỷ lệ mạch có đường kính > 1,5mm tới 95\%.

Tất cả 60 vú được xác định trục mạch bằng siêu âm doppler cầm tay. $100 \%$ QNV đều có nhánh nuôi từ ĐM ngực trong với 45/60 (75\%) nhánh đi vào QNV từ góc phần tư trên trong, $7 / 60(11,67 \%)$ từ phía trên và $8 / 60(13,33 \%)$ từ phía trong. Vạt phức hợp QNV trục mạch ngực trong được thiết kễ với các dạng cuống phụ thuộc theo hướng của mạch xuyên KLS vào QNV: $45 / 60$ (75\%) vạt dạng cuống trên trong, $7 / 60(13,33 \%)$ vạt dạng cuống trên và $8 / 60$ (13,33\%) vạt dạng cuống trong.

Vạt mang QNV trục mạch ngực trong có tỷ lê chiêu dài/rộng trung bình: $2,32 / 1$, lớn nhất tới 4,33/1. Trong đó, 45/60 (75\%) vạt tỷ lệ chiều dài/rộng > 2/1.

Bảng 1. Khoảng cách di chuyển của phức hơp QNV

\begin{tabular}{|c|c|c|}
\hline $\begin{array}{c}\text { Khoảng cách } \\
\text { di chuyển } \mathbf{( c m )}\end{array}$ & $\begin{array}{c}\text { Số lượng } \\
(\mathbf{n = 6 0 )}\end{array}$ & Tỉ lệ $\mathbf{( \% )}$ \\
\hline$<5$ & 2 & 3,33 \\
\hline $5-10$ & 13 & 21,67 \\
\hline $11-15$ & 25 & 41,67 \\
\hline $16-20$ & 12 & 20 \\
\hline$>20$ & 8 & 13,33 \\
\hline Tống & $\mathbf{6 0}$ & $\mathbf{1 0 0}$ \\
\hline
\end{tabular}

Tình trạng sa trề QNV được cải thiện đáng kể với khoảng di chuyển lên trền trung bình QNV: $13.77 \mathrm{~cm}$ với khoảng cách lớn nhất lên tới $26 \mathrm{~cm}$.

Kết quả gần, $55 / 60(91,67 \%)$ QNV có sức sống tốt. $5 / 60(8,33 \%)$ QNV thiểu dưỡng một phần tiến triển mất sắc tố. Không có QNV hoại tử hoàn toàn. Biến chứng chậm liền vết mổ ở $8 / 60$ vú $(13,3 \%)$, toác vết mổ ở $4 / 60$ vú $(6,7 \%)$ đều xảy ra vùng sẹo dọc hoặc ngã ba chũ̃ $T$, giao điểm seo doc-QNV. 46/60 (76,7\%) QNV có cảm giác bình thường. Sau 3 tháng, 8/14 QNV rối loạn cảm hồi phục về bình thường. Chỉ $6 / 60$ vú $(10 \%)$ vẫn giảm cảm giác hoặc dị cảm. 93,3\% vú có hình thể cân đối. 100\% bệnh nhân hài lòng với kết quả phẫu thuật.

\section{BÀN LUÂN}

ĐM ngực trong là nguồn cấp máu chính cho phức hợp QNV, chủ yếu thông qua các nhánh xuyên KLS II, KLS III [5], [6], [7]. Trong nghiên cứu của chúng tôi, trên 10 phim chụp MSCT (20 vú), cũng cho thấy ĐM ngực trong chiếm ưu thế cấp máu QNV với các nhánh xuyên vào QNV đa số thuộc KLS III $(44,44 \%)$ và KLS II $(33,33 \%)$, 
$95 \%$ chúng có đường kính lớn $>1,5 \mathrm{~mm}$, cho thấy khả năng cấp máu đáng tin cậy cho QNV. Trong thiết kế vạt mang phức hợp QNV trục mạch ngực trong, trục mạch được xác định bằng siểu âm doppler cầm tay là nhánh xuyên KLS vào QNV tách từ ĐM ngực trong. Đặc điểm đường đi của chúng sẽ quyết định hướng của vạt và độ rộng vạt. Các nhánh xuyên KLS vào QNV theo 3 hướng với tỉ lệ phía trên trong 45/60 (75\%) vú, phía trên $7 / 60(11,67 \%)$ vú và phía trong $8 / 60$ $(13,33 \%)$ vú, tương ứng với tî lệ các loại cuống vat được sử dụng: cuống trên trong, cuống trên và cuống trong. Nhiều trường hợp trên cùng bệnh nhân, mach đi vào QNV hai bên theo hướng không giống nhau, do đó, đòi hỏi sử dụng dạng cuống vạt khác nhau. Như vậy, bên cạnh tính hằng định và ưu thế cấp máu của ĐM ngực trong, tính linh động trong hình thức sử dụng cuống theo nhánh cấp máu cho QNV (cuống trên, cuống trên trong, cuống trong) là ưu thế của vạt phức hợp QNV trục mạch ngực trong. Trong nghiên của chúng tôi, các nhánh xuyên KLS vào QNV chay dưới bề mặt da trong khoảng $1-26 \mathrm{~mm}$, trung bình $6,9 \mathrm{~mm}$, nên dễ dàng bảo tồn mạch trục mà không yêu cầu độ dày vạt lớn. Sau khi bộc lộ vạt, tổ chức thừa vùng cực ngoài, cực trên và cực dưới có thể cắt bỏ rộng rãi. Bầu vú mới được tạo hình nhờ sắp xếp lại vạt. QNV cũng được chuyển vị lên trên nhờ xoay vạt ra ngoài, lên trên. Dạng cuống vạt ban đầu quyết định góc xoay vạt. Góc xoay nhỏ hơn ở cuống trong, sau đó lớn hơn ở cuống trên trong và lớn nhất ở cuống trên. Góc xoay càng lớn càng dễ gập góc cuống vạt. Trong nghiên cứu của chúng tôii, khoảng cách núm vú- xương đòn trên đường trục núm vú trung bình $29,82 \mathrm{~cm}$, lớn nhất tới $42 \mathrm{~cm}$. Khoảng cách di chuyển QNV lên trên trung bình $13,77 \mathrm{~cm}$, lớn nhất đạt $26 \mathrm{~cm}$ đã minh chứng cho khả năng dịch chuyển rất linh hoạt của vạt.

Tình trang vú phì đại luôn kéo theo sa trễ QNV ở các mức độ khác nhau, là thách thức trong việc di chuyển QNV lên trên. Tình trạng sa trễ càng nhiều, chiều dài vạt mang QNV sẽ càng tăng. Trong y văn, nói đến phì đại khổng lî̀ là nói đến ghép tự do phức hợp QNV, chấp nhận nhược điểm mất chức năng và thẩm mỹ QNV của kỹ thuật này. Với các kỹ thuật thu gọn vú cổ điển bằng vạt mang phức hợp QNV dạng ngẫu nhiên, để đảm bảo cấp máu QNV nằm ở đầu xa vạt, tỷ lệ chiều dài/rộng vạt chỉ giới hạn < 2/1, do vậy, không thể áp dụng cho vú phì đại khổng lồ, sa trễ nặng vì nguy cơ hoại tử QNV [8]. Với kỹ thuật tạo vạt mang phức hợp QNV có trục mạch đảm bảo sức sống QNV tốt hơn ở những vạt có tỉ lệ chiều dài/rộng lớn. Trong nghiên cứu của chúng tôi, tî lệ vú phì đại nhiêu và rất nhiều chiếm $70 \%$, tỉ lệ phì đại khổng lồ $23,3 \%$. Tổng 60 vạt phức hợp QNV trục mạch ngực trong được sử dụng để thu gọn vú, trong đó $45 / 60$ (75\%) vạt có tỉ lệ chiều dài/rộng > 2/1 lớn nhất tới 4,3/1 (26/6cm). 55/60 (91,67\%) QNV có sức sống tốt ngay cả trên vạt tỉ lệ dài/rộng tới 4,3/1, chỉ 5/60 (8,3\%) QNV bị thiểu dưỡng gây bong thượng bì và đặc biệt, không trường hợp nào hoại tử toàn bộ QNV. Kết quả nghiên cứu đã minh chứng cho khả năng cấp máu QNV tốt của vạt dạng trục mạch. Đặc biệt, với mạch trục là nhánh xuyên KLS vào QNV tách từ ĐM ngực trong-nguồn cấp máu chính cho QNV. Các trường hợp thiểu dưỡng QNV xảy ra chủ yếu trong thời gian đầu của nghiên cứu, liên quan chủ yếu đến giảm hồi lưu tĩnh mạch hơn là giảm cấp máu động mạch. Nguyên nhân do chèn ép tĩnh mạch bởi sức căng vết mổ lên vạt hoặc do gập cuống khi xoay ở những vạt kích thước to (cả chiều dài và chiều rộng). Như vậy, trong tạo hình vú bằng vạt mang phức hợp QNV có trục mạch, nguyên tắc "không căng- tension free" cũng cần được tuân thủ như đối với mọi loại tạo hình vạt khác, để đảm bảo không ảnh hưởing lển tuần hoàn vạt. Nếu các vạt ở những trường hợp QNV thiểu dưỡng không phải chịu sức căng lớn, chúng tôi tin chắc rằng với khả năng cấp máu tốt của vạt trục mạch, tỉ lệ QNV sức sống tốt có thể tăng lên đáng kể.

\section{KẾT LUẬN}

Động mạch ngực trong với các nhánh mạch xuyên đa phần qua KLS II, III, là những nhánh cấp máu rất tốt cho phức hợp QNV. Siêu âm doppler cầm tay kết hợp chụp MSCT là phương tiện hỗ trợ rất quan trọng áp dụng cho tất cả bệnh nhân nhằm xác định đường đi, kích thước mạch máu giúp thiết kế vạt trục mach cấp máu cho phức hợp, mang lại hiệu quả tốt trong phẫu thuật thu gọn vú. Phấu thuật thu gọn vú sử dụng vat mang phức hợp QNV truc mach ngực trong có tính linh động cao, có thể sử dụng dưới dạng cuống trên, trên trong hoặc trong áp dụng được cho mọi mức độ vú phì đại, sa trễ đảm bảo sức sống và cảm giác QNV tốt, hình thể vú cân đối.

\section{TÀI LIỆU THAM KHẢO}

1. Trân Thiết Sơn (2006). Tạo hình vú phì đại và sa trễ, Bài giảng phẫu thuật tạo hình, Trường Đại hoc Y Hà Nối.

2. Thorek M. (1989). Possibilities in reconstruction of the human form. Aesthetic plastic surgery, 13, 55-58.

3. Schwarzmann E. (1977). Die technik der mammaplastik: The technique of mammaplasty. 
59, 107-111.

4. Hammond D.C. và Loffredo M. (2012). Breast reduction. Plast Reconstr Surg, 129(5), 829e-839e.

5. Kim D.H., Kim C.W., Lee J.W. và cộng sự. (2019). Distribution of internal thoracic artery perforators: A clincal anatomy study. Clin Anat, 32(4), 471-475.

6. Michelle le Roux C., Kiil B.J., Pan W.-R. và cộng sự. (2010). Preserving the neurovascular supply in the Hall-Findlay superomedial pedicle breast reduction: an anatomical study. Journal of Plastic, Reconstructive \& Aesthetic Surgery, 63(4), 655-662.

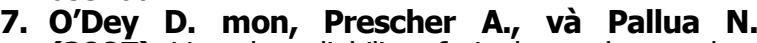
(2007). Vascular reliability of nipple-areola complexbearing pedicles: an anatomical microdissection study. Plast Reconstr Surg, 119(4), 1167-1177.

8. McGregor I.A. và Morgan G. (1973). Axial and random pattern flaps. Br J Plast Surg, 26(3), 202-213.

\section{MộT Số YẾU TỐ LIÊN QUAN ĐẾN THỰC TRANG TRẦ CẢM CỦA NGƯỜI NHIỄM HIV/AIDS ĐANG ĐIỀU TRI ARV TÂI 2 PHÒNG KHÁM NGOẠI TRÚ TỈNH THÁI BÌNH}

\section{TÓM TẮT}

Mục tiêu: Mô tả một số yếu tố liên quan đến trầm cảm của người nhiễm HIV/AIDS đang điêu trị ARV tai 2 phòng khám ngoại trú tỉnh Thái Bình năm 2019. Đối tượng nghiên cứu: bệnh nhân HIV/AIDS người lớn $\geq$ 18 tuổi (gọi tắt là người bệnh) đang điều trị ARV. Phương pháp nghiên cứu: Phương pháp mô tả thông qua cuộc điều tra cắt ngang. Kết quả nghiên cứu: yếu tố liển quan tới trầm của người nhiếm HIV đang điều trị ARV: thất nghiệp, lao động tự do $(\mathrm{OR}=3,4)$; làm việc bán thời gian hoặc theo mùa vụ $(\mathrm{OR}=5,3)$; thu nhập hàng tháng dưới 3 triệu đồng $(\mathrm{OR}=9,6)$; có sử dụng ma túy $(\mathrm{OR}=2,9)$; kinh tế hộ gia đình thuộc diện nghèo, không đủ ăn $(O R=7,5)$; không được hố trợ điều trị $(\mathrm{OR}=3,2)$; bị kỳ thị, phân biêt đối xử $(O R=4,0)$; găp phải tác dụng phụ của thuốc ARV $(\mathrm{OR}=2,5)$; đang điều trị các bệnh khác $(\mathrm{OR}=5,9)$; kết quả xét nghiệm $\mathrm{T}-\mathrm{CD} 4$ lần gần nhất > 500 tế bào $(\mathrm{OR}=2,5)$

Tư khóa: Yếu tố liên quan đến trầm cảm; HIV/AIDS; Thái Bình.

\section{SUMMARY \\ DEPRESSION SITUATION OF HIV/AIDS PATIENTS WHO TREATED HIV/AIDS WITH ARV AT 2 OUTPATIENT CLINICS IN THAI BINH PROVINCE}

Objectives: Describe related factors associated with depression of HIV/AIDS patients who treated HIV/AIDS with ARV at 2 outpatient clinics in Thai Binh province in 2019. Subjects: HIV/AIDS patients adults $\geq 18$ years old being treated with ARV. Method: Descriptive method through cross-sectional survey. Results: related factor of depression was: unemployment, self-employed $(\mathrm{OR}=3.4)$; working part-time or seasonally $(\mathrm{OR}=5,3)$; monthly income

*Trường Đại hơ Y Dược Thái Binh

Chịu trách nhiệm chính: Ngô Văn Mạnh

Email: manhsdh@gmail.com

Ngày nhận bài: 12.7.2021

Ngày phản biên khoa hoc: 30.8.2021

Ngày duyệt bài: 13.9.2021

\section{Ngô Văn Mạnh*, Bùi Thị Huyền Diệu*}

less than 3 million VND ( $O R=9.6)$; drug use $(O R=2.9)$; household economy is poor, not enough to eat $(\mathrm{OR}=7.5)$; no treatment support $(\mathrm{OR}=3.2)$; stigma, discrimination $(O R=4,0)$; experiencing ARV side effects $(O R=2.5)$; currently being treated for other diseases $(\mathrm{OR}=5.9)$; most recent $\mathrm{T}-\mathrm{CD} 4$ test result > 500 cells (OR $=2.5$ )

Keywords: Factors associated of depression; HIV/AIDS; Thai Binh

\section{I. ĐẶT VẤN ĐỀ}

Hơn 30 năm qua, kể từ khi phát hiện ra HIV cho đến nay, cộng đồng quốc tế đã nỗ lực rất lớn trong công tác chăm sóc, điều trị HIV/AIDS nhằm đẩy lùi sự gia tăng của đại dịch AIDS và đã thu được nhiều kết quả đáng ghi nhận đó là sự phát triển tổng thể của dịch AIDS toàn câu có vẻ như đã ổn định. Số người nhiễm mới HIV hàng năm giảm xuống đáng kể từ cuối những năm 1990 và tử vong liên quan AIDS ít dân do việc mở rộng điều trị kháng HIV.

Cùng với sự điều trị người bệnh HIV cũng được chăm sóc, hỗ trợ nhằm tăng cường sức khỏe thể chất. Tuy nhiển, khi sức khỏe thể chất được đảm bảo thì sức khỏe tâm thân của người nhiễm HIV cũng là một trong những vấn đề cân được quan tâm và can thiệp nhằm nâng cao hiệu quá điêuu trị cho họ. Người bệnh nhiễm HIV có thể gặp phải những ảnh hưởng tâm lý xã hội, các vấn đề sức khỏe tâm thân bắt đâu từ rất sớm ngay khi có chẩn đoán ban đâu và có thể phát sinh trong cả thời gian điêu trị bệnh. Các vấn đề phổ biến thường gặp phải là trâm cảm, lo âu và làm dụng các chất gây nghiện. Trong đó, trầm cảm là biến chứng thần kinh phổ biến nhất ở bệnh nhân nhiễm HIV và hạn chế đáng kể chất lượng cuộc sống của bệnh nhân HIV/AIDS [2].

Tại Việt Nam, các nghiên cứu đánh giá về vấn đề trầm cảm ở người bệnh nhiễm HIV đã được 